\title{
LXXVIII. A quantitative relation between the range of the $\alpha$ particles and the number of charges emitted during disintegration
}

\section{A. van den Broek}

To cite this article: A. van den Broek (1913) LXXVIII. A quantitative relation between the range of the $\alpha$ particles and the number of charges emitted during disintegration, Philosophical Magazine Series 6, 25:149, 740-742, DOI: 10.1080/14786440508637391

To link to this article: http://dx.doi.org/10.1080/14786440508637391

曲 Published online: 20 Apr 2009.

Submit your article to this journal

Џll Article views: 3

Q View related articles 
LXXVIII. A Quantitative Relation between the Range of the a Particles and the Number of Charges emitted during Disintegration. By A. vaN DEN BROEK *.

TN 1907 Rutherford $\dagger$ observed that there appeared to be a 1 relation between the period of transformation of a product and the velocity of the $\alpha$ rays expelled from it. In 1911 Geiger and Nuttall $\$$ showed that in the great majority of cases the range of the $\alpha$ particle increased with the decrease of the period of transformation. Plotting the logarithm of the range of the $\alpha$ particle against the logarithm of the constant of transformation, the products of the uranium and radium series lie nearly on a straight line. In the thorium and actinium series again most of the products lie approximately on a straight line parallel with the line showing the relation for the uranium-radium series. As Rutherford $\S$ remarks, "The relation found by Geiger is of exceptional interest, for it supplies undoubted evidence that a connexion exists between two of the fundamental magnitudes in radioactive transformation."

Similar relations were given by Swinne $\|$ and $\mathrm{H}$. A. Wilson T.

Between the velocity of the $\alpha$ rays and the number of charges expelled there appears also to be a similar relation. Plotting the logarithm of the initial velocity of the $\alpha$ particle against the number of charges expelled, the products of all series lie nearly on a straight line. As the values for all series, but not for analogous products in each, are the same, the initial value for each series can be chosen to fit in well. Of course it is not known if these are really the first.

Two difficulties immediately arise. Firstly, $\mathrm{RaC}$ and Th C (or B) were proved by Fajans ** and by Marsden and Barratt $\dagger+$ to give off two branches of products. It seems, however, that for one branch the relation holds good, while for the other a reversal, and probably a regular one, seems to take place. In this case, on the $\mathrm{Ra}$ series one product more for each branch ought to be introduced; for the thorium series, however, more.

* Communicated by the Author.

$\dagger$ Phil. Mag. xiii. p. 110 (1907).

† Phil. Mag. xxil. p. 613 (1911) ; xxiii. p. 439 (1912); xxiv. p. 647 (1912).

\$ 'Radioactive Substances and their Radiations,' p. 609, Cambridge 1913.

II Phys. Zeitsch. xiii. p. 14 (1912).

If Phil. Nag. xxiii. p. 981 (1912).

** Plys. Zeitsch. x. p. 697 (1909).

†† Proc. Phys. Soc. xxiv. p. 8 (1911). 
The actinium series, too, must then be complex as the same reversal exists here. Indeed, Mlle. Blanquies * found some evidence that the a rays emitted from actinium $\mathrm{C}$ are complex.

That uranium, too, is complex was observed by Antonoff $\dagger$. The branch product $\mathrm{Ur} \mathrm{Y}$ emits soft $\beta$ rays, and some evidence was found that it emitted $\alpha$ rays. As Rutherford $\ddagger$ remarks, "The possibility of a branch produot of uranium is of great interest, as affording a possible explanation of the origin of actinium." If now we suppose Ur Y - as emitting $\alpha+\beta$ raysto consist of two products, one emitting $\alpha$ rays, the other emitting $\beta$ rays (and the same must be supposed for $\mathrm{Ra}$, Th X, Ac X, Ra Ao-which all emit both $\alpha$ and $\beta$ rays), then the product of Ur Y 2 falls tugether with Act. and might be identical with it.

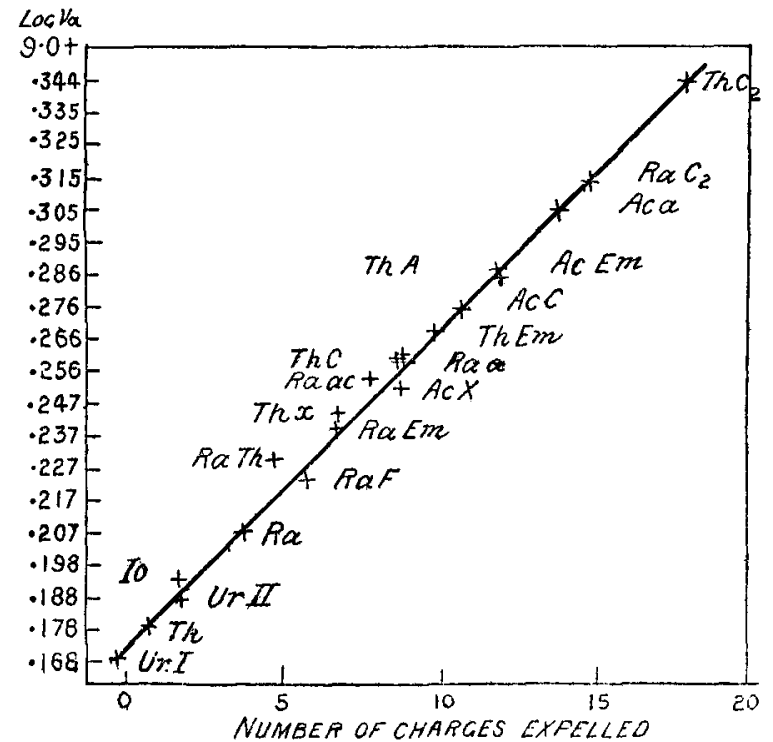

If we accept for UrII the value given by Geiger and Nuttall, then the uranium series cannot unite in the radium series, as the values for U II and Io are nearly identical. If, however, the range $2.90 \mathrm{~cm}$. is altributed to $\mathrm{Ur} Y$ and in part that of $2 \cdot 50$ to Ur II also, while the range $\pm 1 \cdot 6 \mathrm{~cm}$. found by Friedmann $\S$ is attributed to Ur also as emitting two $\alpha$ rays of

* C. R. cli. p. 57 (1910); Le Radium, vi. p. 230 (1909), vii, p. 159 (1910).

$\dagger$ Phil. Mag. xxil. p. 419 (1911).

I Loc. cit. p. 45.

\$ Wien. Ber. cxx. p. 1361 (1911).

Phil. Mag. S. 6. Vol. 25. No. 149. May 1913. 3 E 
different range for the two different branches, then also the radium series can be deduced from the uranium series. Of course, such a deduction is very hypothetical.

Recently von Hevesy ${ }^{*}$, and also Fajans + , proved that a relation exists between the expulsion of $a$ and $\beta$ rays and the change in chemical properties. As the atomic weight of the products also depends on the number of $\alpha$ particles expelled and finally "a relation of a similar though not nearly so definite a character as that found by Geiger for the $\alpha$ rays appears to hold between the velocity of expulsion of $\beta$ particles and the period of transformation of the product concerned" $\ddagger$, it seems not improbable that all radioactive constants depend on the number of charges expelled only.

\section{Summary.}

The following relations seem to exist, first, between the initial velocity of the $\alpha$ rays and the number of charges expelled during disintegration $: \log \mathrm{V}_{\alpha}=\mathrm{A}+n \mathrm{~B}$, and second, between the period of transformation and the number of charges expelled: $\log \lambda=C+n \mathrm{I}$, where $\mathbf{B}$ and $\mathrm{D}$ are general constants, $\mathrm{A}$ and $\mathrm{C}$ special constants for each series, and $n$ the number of charges expelled.

Noordwrk-Zee, Duinhoeve, Fubruary 1913.

LXXIX. The Effect of Interionic Forces on the Osmotic Pressure of Electrolytes. By S. R. MILNER, D.Sc., Lecturer in Physics, The University of Sheffield $\$$.

7 PHE osmotic pressure of dilute solutions of inorganic 1 electrolytes, as determined from the lowering of the freezing-point, is always nearly, but not quite, as great as it would be if the dissociation of the electrolyte were complete. The explanation given by Arrhenius in 1887 that in such electrolytes an appreciable fraction of the molecules remains undissociated, is still the one which is generally accepted. This theory is strongly supported by the agreement of the values of the dissociation calculated from freezing-point and from conductivity measurements, but it gives results for its variation with the concentration which are, as is well known, wholly at variance with the law of mass-action; and although many attempts have been made to explain this discrepancy

* Phys. Zeitsch. xiv. p. 50 (1913).

† Phys. Zeitsch. xiv. p. 137 (1913).

\pm Loc. cit. p. 610.

$\$$ Communicated by the Author. 